\title{
The Immunogenicity and Immune Tolerance of Pluripotent Stem Cell Derivatives
}

OPEN ACCESS

Edited by:

Reem Al-Daccak,

Institut national de la santé et de la recherche médicale (INSERM),

France

Reviewed by:

Ralf Dressel,

Universitätsmedizin Göttingen,

Germany

Federica Casiraghi,

Istituto Di Ricerche Farmacologiche

Mario Negri, Italy

${ }^{*}$ Correspondence:

Xuemei Fu

fxmzj2004@163.com;

Yang $X u$

yangxu@ucsd.edu

tThese authors have contributed equally to this work.

Specialty section:

This article was submitted to Alloimmunity and Transplantation,

a section of the journal

Frontiers in Immunology

Received: 30 March 2017

Accepted: 17 May 2017

Published: 02 June 2017

Citation:

LiU X, Li W, Fu X and Xu Y (2017) The

Immunogenicity and Immune

Tolerance of Pluripotent

Stem Cell Derivatives.

Front. Immunol. 8:645.

doi: 10.3389/fimmu.2017.00645

\begin{abstract}
Xin $\mathrm{Liu}^{1,2 \dagger}$, Wenjuan $\mathrm{Li}^{1 \dagger}$, Xuemei $\mathrm{Fu}^{3 *}$ and Yang $\mathrm{Xu}^{1,2 *}$
${ }^{1}$ Center for Regenerative and Translational Medicine, Guangdong Provincial Academy of Chinese Medical Sciences, The Second Affiliated Hospital of Guangzhou University of Chinese Medicine, Guangzhou, China, ${ }^{2}$ Division of Biological Sciences, University of California, San Diego, La Jolla, CA, United States, ${ }^{3}$ The Eighth Affiliated Hospital of Sun Yat-sen University, Shenzhen, China
\end{abstract}

Human embryonic stem cells (hESCs) can undergo unlimited self-renewal and differentiate into all cell types in human body, and therefore hold great potential for cell therapy of currently incurable diseases including neural degenerative diseases, heart failure, and macular degeneration. This potential is further underscored by the promising safety and efficacy data from the ongoing clinical trials of hESC-based therapy of macular degeneration. However, one main challenge for the clinical application of hESC-based therapy is the allogeneic immune rejection of hESC-derived cells by the recipient. The breakthrough of the technology to generate autologous-induced pluripotent stem cells (iPSCs) by nuclear reprogramming of patient's somatic cells raised the possibility that autologous iPSC-derived cells can be transplanted into the patients without the concern of immune rejection. However, accumulating data indicate that certain iPSC-derived cells can be immunogenic. In addition, the genomic instability associated with iPSCs raises additional safety concern to use iPSC-derived cells in human cell therapy. In this review, we will discuss the mechanism underlying the immunogenicity of the pluripotent stem cells and recent progress in developing immune tolerance strategies of human pluripotent stem cell (hPSC)-derived allografts. The successful development of safe and effective immune tolerance strategy will greatly facilitate the clinical development of hPSC-based cell therapy.

Keywords: embryonic stem cells, induced pluripotent stem cells, cell therapy, allogeneic immune rejection, immunogenicity, immune tolerance

\section{THE PROMISE OF PLURIPOTENT STEM CELL (PSC)-DERIVED CELLS IN CELL THERAPY OF MAJOR HUMAN DISEASES}

The successful establishment of human embryonic stem cells (hESCs) from the inner cell mass of the human blastocyts has opened up a new era in regenerative medicine (1). Significant progress has been achieved in developing protocols to differentiate hESCs into various lineages of biologically active cells such as neural cells, pancreatic $\beta$ cells, retinal pigmented epithelial (RPE) cells, cardiomyocytes, and hepatocytes (2). Three of such hESC-derived cells have entered clinical trial to treat macular degeneration, spinal cord injury, and type 1 diabetes (3). In addition, these clinical trials have provided promising data on the safety and efficacy of hESC-based cell therapy of macular degeneration, further supporting the great potential of the clinical application of hESC (4-6). 
However, one of the main bottlenecks that hinder the clinical development of hESC-based therapy is the allogeneic immune rejection by the recipient. While current immune suppression regimen can effectively prevent allogeneic immune rejection, the persistent use of immune suppressants is toxic to patients, and can greatly increase the risk of infection and cancer, especially in patients infected with cytomegalovirus and the herpes viruses (7). In addition, immune suppressants are toxic to some of the hESC-derived progenitor cells (8).

The development of induced pluripotent stem cells (iPSCs) by reprogramming somatic cells into pluripotent state with defined transcriptional factors has provided another source of PSC for human cell therapy (9-12). When compared with hESC-based cell therapy, iPSCs were thought to provide certain advantages, including the lack of ethic concerns and immune rejection by the recipient (13). However, recent studies have demonstrated the increased genomic instability, epigenetic abnormality, and immunogenicity of iPSCs, raising safety concerns of iPSC-based cell therapy $(14,15)$. Therefore, to improve the feasibility of iPSC-based therapy, it is important to understand the underlying reprogramming mechanism and develop strategies to minimize these safety concerns.

\section{THE IMMUNE RESPONSES TO ALLOGENEIC ESCS AND THEIR DERIVATIVES}

The polymorphic major histocompatibility complex (MHC) molecules are distinct between individuals, leading to the massive T cell-mediated immune response and rejection of the transplanted allogeneic cells (16). There are two classes of MHC molecules, MHC class I molecules that are expressed on most of the nucleated cells and MHC class II molecules that are expressed primarily on antigen presenting cells (16). MHC class I molecules are required to activate $\mathrm{CD}^{+}$cytotoxic $\mathrm{T}$ cells that can destroy the target cells, and MHC class II molecules are required to activate $\mathrm{CD} 4^{+}$helper $\mathrm{T}$ cells that are critical to activate other immune cells including cytotoxic T cells (16). In addition, certain cell types lacking the expression of MHC class I molecules such as stem cells and cancer cells are rejected by natural killer (NK) cells (17).

While mouse ESCs do not express detectable MHC Class I and Class II molecules $(18,19)$, hESCs express MHC Class I molecules but not MHC Class II molecules, and hESCs cannot directly activate $\mathrm{T}$ cells in vitro and in vivo (20-23). However, hESCs can be immune rejected by various mechanisms after transplantation. First, allogeneic NK cells can eliminate mouse and human ESCs in vitro $(24,25)$. Second, while ESCs do not directly activate allogeneic $\mathrm{T}$ cell through the interaction between allogeneic MHC molecules and TCR, ESCs express immunogenic antigens such as MHC Class I molecules and Oct4 that can indirectly activate $\mathrm{T}$ cells through antigen presenting cells $(22,23,26)$. Third, after transplantation, both mouse and human ESCs cannot maintain the pluripotent state and will undergo spontaneous differentiation into various cell types that express MHC molecules, leading to robust T-dependent allogeneic rejection $(27,28)$. Therefore, hESCs and their derivatives will be immune rejected when transplanted into allogeneic recipients.
While it has been suggested that ESCs might have immune modulatory functions in treating certain diseases such as myocardial infarction (29), ESCs pose a serious teratoma risk after transplantation and thus are unlikely to be used directly in therapy. Therefore, the major effort should be devoted to understanding the allogeneic immune responses to hESC-derived cells that have no teratoma risk. There has been limited progress in this area of research due to the lack of robust animal models to study the human immune responses to hESC-derived cells. Recent application of humanized mice reconstituted with functional human immune system, which are generated by transplanting human fetal thymus and $\mathrm{CD} 34^{+}$fetal liver cells, has made this research more feasible (30). In support of this notion, recent studies demonstrated that the humanized mice could mount vigorous allogeneic immune rejection of hESC-derived cells (31).

\section{THE IMMUNOGENICITY OF iPSCS AND THEIR DERIVATIVES}

The breakthrough of induced pluripotency to reprogram somatic cells from patients into PSC has raised the possibility that the cells derived from patient-specific iPSCs are autologous and thus will not be immune rejected by the patient (32). However, hiPSCs can be rejected by allogeneic and autologous NK cells (33). In addition, accumulating data have demonstrated that cells derived from iPSCs can be immunogenic to the autologous immune system. Using an inbred C57/BL6 (B6) transplantation mouse model, Zhao et al. (27) demonstrated that cells derived from B6 iPSCs can activate syngeneic $\mathrm{T}$-dependent immune responses due to the deregulated expression of immunogenic proteins such as the tumor antigen Hormad1. This conclusion is supported by a following study, which also demonstrated that the endothelial cells derived from $\mathrm{B} 6$ iPSCs are immune tolerated by B6 mice (34). However, the iPSC-derived endothelial cells express high levels of immune suppressive cytokines such as IL-10 and are immune rejected in B6 mice when treated with anti-IL-10 antibody, supporting the notion that these iPSC-derived endothelial cells are intrinsically immunogenic (34). In addition, cardiomyocytes derived from B6 iPSCs are highly immunogenic when transplanted into the B6 mice subcutaneously (35). In the same study, the authors derived $\mathrm{GFP}^{+}$skin tissue from $\mathrm{B} 6$ chimeric mice generated by injecting GFP-expressing B6 iPSCs into B6 blastocyts and found no immune rejection when the $\mathrm{GFP}^{+}$skin tissue was grafted to new $\mathrm{B} 6$ mice. However, these B6 iPSC-derived skin tissues have already been preselected by the $\mathrm{B} 6$ immune system in the chimeric mice, and thus the skin graft will not be rejected by B6 immune system when transplanted onto new B6 mice. In support of this notion, GFP is a foreign protein and immunogenic to B6 mice when expressed in the skin, and GFP-expressing skin tissues of GFP transgenic B6 mice are immune rejected when grafted to the $\mathrm{B} 6$ mice (36-38).

Several recent studies have argued that iPSC-derived cells are not immunogenic to the isogenic or autologous immune system. By transplanting cells derived from B6 iPSCs under the kidney capsule of B6 mice, Guha et al. (39) concluded that various lineages of iPSC-derived cells exhibit no immunogenicity. In addition, the transplantation of iPSC-derived neural cells in the brain of autologous monkeys leads to minimum immune response (40). To resolve 
this apparent discrepancy, a recent study showed that the lack of immunogenicity of B6-derived iPSCs transplanted under the kidney capsule is due to the absence of functional antigen presenting cells in the kidney, and the cotransplantation of B6 iPSC-derived cells with functional B6 dendritic cells under the kidney capsule leads to robust immune rejection (41). Therefore, the presence of functional antigen presenting cells at the transplantation site is required to reveal the immunogenicity of iPSC-derived cells. In further support of the conclusion that iPSC-derived cells can be immunogenic, using a humanized mouse model reconstituted with human immune system, Zhao et al. demonstrated the differential immunogenicity of human iPSC-derived cells. In this context, iPSC-derived smooth muscle cells are highly immunogenic to the autologous immune system due to the deregulated expression of immunogenic proteins, but iPSC-derived RPE cells are not immunogenic to the autologous immune system even when transplanted into smooth muscle (28). Importantly, the lack of immunogenicity of iPSC-derived RPE cells has been recapitulated in the only one treated patient in the clinical trial to use autologous iPSC-derived RPE cells to treat macular degeneration (42).

There are several mechanisms to explain the immunogenicity of iPSCs. First, compared to ESCs, iPSCs are epigenetically abnormal and inherited epigenetic signature of parental cells (43-45). The epigenetic abnormalities could explain the abnormal expression of immunogenic proteins expressed during the differentiation of iPSCs but not ESCs $(27,28)$. The impact of this epigenetic mechanism on the deregulated expression of immunogenic proteins could be cell lineage specific as observed in the differentiation of hiPSCs into RPEs and smooth muscle cells (28). Second, somatic coding mutations are detected in all iPSC lines tested, and the protein coding mutations can create new immunogenic determinants like the tumor antigens developed in cancer cells $(46,47)$. Third, the genomic translocation detected in the iPSCs will create fusion proteins and new immunogenic determinants (14). Therefore, in addition to the immunogenicity of iPSC-derived cells, a more serious safety concern of the iPSCbased cell therapy is the genomic instability of iPSCs that can greatly increase cancer risk (14). In support of this notion, the first clinical trials of iPSC-based cell therapy was terminated after the enrollment of the first patient due to the discovery of coding mutations in cancer related genes in the iPSCs reprogrammed from the somatic cells of the second patient (42). This cancer concern poses a serious bottleneck for developing individualized cell therapy using patients' own iPSC. Instead, future effort will be devoted to establish genetically stable iPSC cell bank, and the iPSC line with the best match to the patient's HLA will be used for cell therapy. In this context, the clinic development of allogeneic iPSC will face the same challenge of immune rejection as hESCs.

\section{STRATEGIES TO PROTECT ALLOGENEIC HUMAN PLURIPOTENT STEM CELL (hPSC)-DERIVED CELLS FROM IMMUNE REJECTION}

While immune suppressant regimen can effectively suppress allogeneic immune responses, the persistent use of immune suppressants will significantly increase the risk of infection and cancer, especially in the majority of the population with Cytomegalovirus infection (7). In addition, the immune suppressants are toxic to some hESC-derived cells such as neural progenitor cells (48). Therefore, to realize the potential of hESC-based therapy, it is important to develop safe and effective immune tolerance strategy of allogeneic hESC-derived cells.

Allogeneic immune rejection is primarily mediated by $\mathrm{T}$ celldependent immune responses. Previous studies have demonstrated that standard immunosuppressive drug regimens can significantly reduce the immune response to prolong the survival of hESCderived xenografts but cannot eventually prevent immune rejection $(49,50)$. Based on our knowledge of the pathways critical for T-cell activation, it is possible to induce immune tolerance of hESC-derived allogeneic cells by disrupting the $\mathrm{T}$ cell costimulatory pathways, such as CD28-CD80/CD86 and CD40-CD40L pathways $(51,52)$. PD-L1 also plays a central role in maintaining T cell anergy and preventing autoimmunity (51). PD-L1 (B7-H1, CD274) interacts with programmed cell death 1 (PD-1), which is an inhibitory receptor expressed on activated T cells, NK cells, and $\mathrm{B}$ cells, and this interaction leads to negative regulation of lymphocyte activation (53), and PD-1 is required for the induction of T-cell tolerance by dendritic cells (54). Therefore, it is possible to develop immune tolerance strategy by modulating these costimulatory and inhibitory pathways.

A recent study has shown that treatment of mice with cytotoxic T lymphocyte antigen 4-Ig (CTLA4-Ig), which binds to the B7 family of costimulatory molecules CD80 and CD86 with higher affinity and avidity than CD28, and anti-CD40L blocking CD40CD40L pathway not only prolonged hESC-derived pancreatic endoderm graft survival but also resulted in the establishment of immune tolerance of the xeno-immune system (55). A similar study also showed that the blockade of costimulatory pathways with antibodies significantly prolonged the engraftment of cells derived from human ESCs and iPSCs in mice without inhibiting the ability of the recipient to respond to other foreign antigens (56). However, in contrast to the naive T cells of a mouse model, up to $50 \%$ of alloreactive $\mathrm{T}$ cells in a human receiving transplants may display a memory phenotype $(57,58)$, and the allogeneic immune tolerance of mouse immune system can be achieved more easily than human immune system. Therefore, the immune tolerance strategy developed in mouse models must be re-evaluated in the context of human immune system.

To address this bottleneck, recent studies have employed humanized mice reconstituted with human immune system to study human immune responses to cells derived from hPSCs $(28,31,51,53,54,59)$. The human immune system of humanized mice can robustly reject allogeneic cells derived from human embryonic stem cells (hESCs), and thus can be used to vigorously test immune tolerance strategy (31). Using humanized mice, it was demonstrated that the expression of CTLA4-Ig and PD-L1 in the cells derived from genetically modified hESCs can effectively protect these cells from allogeneic human immune responses without inducing systemic immune suppression (31). Neither the expression of CTLA4-Ig nor PD-L1 alone is sufficient to provide immune protection, consistent with human clinical data (31, 58). Because the CTLA4-Ig/PD-L1-expressing cells are immune 
evasive, they are susceptible to infection and cancer. To minimize the risk, the co-expression of the suicidal thymidine kinase gene in these cells enables the efficient elimination of the graft with FDA-approved TK-targeting drug (59). These studies supported the feasibility to develop safe and effective strategy to protect hESC-derived allografts from immune rejection.

In addition to the modulation of the $\mathrm{T}$ cell costimulatory and inhibitory pathways, other strategies have been explored to confer immune protection of allogeneic hESC-derived allografts. One such attempt is to reduce the immunogenicity of hESC-derived cells by disrupting the expression of MHC molecules that elicit allogeneic T-cell responses. For example, knockdown of both HLA class I and class II in hESC could provoke T-cell ignorance in vitro and protection from xenogeneic immune rejection in vivo (60-62). Disruption of MHC class II transactivator in hESCs leads to the silencing of HLA class II expression in differentiated cells, such genetic modification could confer protection from the allogeneic helper $\mathrm{T}$ cells $(63,64)$. While the immune evasive properties of these cells lacking HLA I and II molecules have been confirmed in vitro and in mice, they remain to be evaluated in the context of a human immune system.

\section{CONCLUSION}

Despite their potential in curing major diseases and the encouraging clinical trial data, one of the key challenges for hPSC-based therapy is the immune rejection by the recipient.

\section{REFERENCES}

1. Thomson JA, Itskovitz-Eldor J, Shapiro SS, Waknitz MA, Swiergiel JJ, Marshall VS, et al. Embryonic stem cell lines derived from human blastocysts. Science (1998) 282:1145-7. doi:10.1126/science.282.5391.1145

2. Fu X, Xu Y. Self-renewal and scalability of human embryonic stem cells for human therapy. Regen Med (2011) 6:327-34. doi:10.2217/rme.11.18

3. Fu X, Cui K, Yi Q, Yu L, Xu Y. DNA repair mechanisms in embryonic stem cells. Cell Mol Life Sci (2017) 74:487-93. doi:10.1007/s00018-016-2358-Z

4. Song WK, Park KM, Kim HJ, Lee JH, Choi J, Chong SY, et al. Treatment of macular degeneration using embryonic stem cell-derived retinal pigment epithelium: preliminary results in Asian patients. Stem Cell Reports (2015) 4:860-72. doi:10.1016/j.stemcr.2015.04.005

5. Schwartz SD, Hubschman JP, Heilwell G, Franco-Cardenas V, Pan CK, OstrickRM, et al. Embryonic stem cell trials for macular degeneration: a preliminary report. Lancet (2012) 379:713-20. doi:10.1016/S0140-6736(12)60028-2

6. Schwartz SD, Regillo CD, Lam BL, Eliott D, Rosenfeld PJ, Gregori NZ, et al. Human embryonic stem cell-derived retinal pigment epithelium in patients with age-related macular degeneration and Stargardt's macular dystrophy: follow-up of two open-label phase 1/2 studies. Lancet (2015) 385:509-16. doi:10.1016/S0140-6736(14)61376-3

7. Fishman JA. Overview: cytomegalovirus and the herpesviruses in transplantation. Am J Transplant (2013) 13:1-8. doi:10.1111/ajt.12002

8. Herberts CA, Kwa MS, Hermsen HP. Risk factors in the development of stem cell therapy. J Transl Med (2011) 9:29-29. doi:10.1186/1479-5876-9-29

9. Takahashi K, Yamanaka S. Induction of pluripotent stem cells from mouse embryonic and adult fibroblast cultures by defined factors. Cell (2006) 126:663-76. doi:10.1016/j.cell.2006.07.024

10. Takahashi K, Tanabe K, Ohnuki M, Narita M, Ichisaka T, Tomoda K, et al. Induction of pluripotent stem cells from adult human fibroblasts by defined factors. Cell (2007) 131:861-72. doi:10.1016/j.cell.2007.11.019

11. Yu J, Vodyanik MA, Smuga-Otto K, Antosiewicz-Bourget J, Frane JL, Tian S, et al. Induced pluripotent stem cell lines derived from human somatic cells. Science (2007) 318:1917-20. doi:10.1126/science.1151526
With extensive data of the transplantation immunology in mice and the accumulating data on the human immune responses to hESC-derived allografts in humanized mice, it has become apparently feasible to develop safe and effective strategies to induce graft-specific immune tolerance in the near future. Such achievement will greatly facilitate the clinic development of hPSC-based therapy.

\section{AUTHOR CONTRIBUTIONS}

All authors listed have made substantial, direct, and intellectual contribution to the work and approved it for publication.

\section{FUNDING}

This study is supported by the National Natural Science Foundation of China (Nos. 815300045, 81373166, and 81430032), a grant from the National High-tech R\&D Program (863 Program No. 2015AA020310), Guangdong Provincial Key Laboratory of Cancer Immunotherapy, Guangdong Province Key Special Science and Technology Project (2015B020225004), South Wisdom Valley Innovative Research Team Program (2014) No. 365, Shenzhen Municipal Science and Technology Innovation Council (20140405201035), one China Postdoctoral Science Foundation fellowship (2015M582371), one China Scholarship Council Grant (201408440144), and California Institute for Regenerative Medicine (RT3-07899).

12. Park IH, Zhao R, West JA, Yabuuchi A, Huo H, Ince TA, et al. Reprogramming of human somatic cells to pluripotency with defined factors. Nature (2008) 451:141-6. doi:10.1038/nature06534

13. Ilic D, Ogilvie C. Concise review: human embryonic stem cells-what have we done? what are we doing? where are we going? Stem Cells (2017) 35:17-25. doi:10.1002/stem.2450

14. Yoshihara M, Hayashizaki Y, Murakawa Y. Genomic instability of iPSCs: challenges towards their clinical applications. Stem Cell Rev Rep (2017) 13:7-16. doi:10.1007/s12015-016-9680-6

15. Sebban S, Buganim Y. Nuclear reprogramming by defined factors: quantity versus quality. Trends Cell Biol (2016) 26:65-75. doi:10.1016/j.tcb.2015.08.006

16. Marino J, Paster J, Benichou G. Allorecognition by T lymphocytes and allograft rejection. Front Immunol (2016) 7:582. doi:10.3389/fimmu.2016.00582

17. Chidgey AP, Boyd RL. Immune privilege for stem cells: not as simple as it looked. Cell Stem Cell (2008) 3:357-8. doi:10.1016/j.stem.2008.09.011

18. Boyd AS, Wood KJ. Variation in MHC expression between undifferentiated mouse ES cells and ES cell derived insulin-producing cell clusters. Transplantation (2009) 87:1300-4. doi:10.1097/TP.0b013e3181a19421

19. Jaffe L, Robertson EJ, Bikoff EK. Distinct patterns of expression of MHC class I and beta 2-microglobulin transcripts at early stages of mouse development. J Immunol (1991) 147:2740.

20. English K, Wood KJ. Immunogenicity of embryonic stem cell-derived progenitors after transplantation. Curr Opin Organ Transplant (2011) 16:90-5. doi:10.1097/MOT.0b013e3283424faa

21. Draper JS, Pigott C, Thomson JA, Andrews PW. Surface antigens of human embryonic stem cells: changes upon differentiation in culture*. J Anat (2002) 200:249-58. doi:10.1046/j.1469-7580.2002.00030.x

22. Li L, Baroja ML, Majumdar A, Chadwick K, Rouleau A, Gallacher L, et al. Human embryonic stem cells possess immune-privileged properties. Stem Cells (2004) 22:448-56. doi:10.1634/stemcells.22-4-448

23. Drukker M, Katchman H, Katz G, Even-Tov Friedman S, Shezen E, Hornstein E, et al. Human embryonic stem cells and their differentiated derivatives are less susceptible to immune rejection than adult cells. Stem Cells (2006) 24:221-9. doi:10.1634/stemcells.2005-0188 
24. Dressel R, Nolte J, Elsner L, Novota P, Guan K, Streckfuss-Bömeke K, et al. Pluripotent stem cells are highly susceptible targets for syngeneic, allogeneic, and xenogeneic natural killer cells. FASEB J (2010) 24:2164-77. doi:10.1096/ f. $09-134957$

25. Perez-Cunningham J, Ames E, Smith RC, Peter AK, Naidu R, Nolta JA, et al. Natural killer cell subsets differentially reject embryonic stem cells based on licensing. Transplantation (2014) 97:992-8. doi:10.1097/TP. 0000000000000063

26. Dhodapkar KM, Feldman D, Matthews P, Radfar S, Pickering R, Turkula S, et al. Natural immunity to pluripotency antigen OCT4 in humans. Proc Natl Acad Sci U S A (2010) 107:8718-23. doi:10.1073/pnas.0915086107

27. Zhao T, Zhang ZN, Rong Z, Xu Y. Immunogenicity of induced pluripotent stem cells. Nature (2011) 474:212-5. doi:10.1038/nature10135

28. Zhao TB, Zhang ZN, Westenskow PD, Todorova D, Hu Z, Lin TX, et al. Humanized mice reveal differential immunogenicity of cells derived from autologous induced pluripotent stem cells. Cell Stem Cell (2015) 17:353-9. doi:10.1016/j.stem.2015.07.021

29. Yuan X, Zhang H, Wei YJ, Hu SS. Embryonic stem cell transplantation for the treatment of myocardial infarction: immune privilege or rejection. Transpl Immunol (2007) 18:88-93. doi:10.1016/j.trim.2007.05.003

30. Shultz LD, Brehm MA, Garcia-Martinez JV, Greiner DL. Humanized mice for immune system investigation: progress, promise and challenges. Nat Rev Immunol (2012) 12:786-98. doi:10.1038/nri3311

31. Rong ZL, Wang MY, Hu Z, Stradner M, Zhu SY, Kong HJ, et al. An effective approach to prevent immune rejection of human ESC-derived allografts. Cell Stem Cell (2014) 14:121-30. doi:10.1016/j.stem.2013.11.014

32. Yamanaka S. Strategies and new developments in the generation of patientspecific pluripotent stem cells. Cell Stem Cell (2007) 1:39-49. doi:10.1016/j. stem.2007.05.012

33. Kruse V, Hamann C, Monecke S, Cyganek L, Elsner L, Hübscher D, et al. Human induced pluripotent stem cells are targets for allogeneic and autologous natural killer (NK) cells and killing is partly mediated by the activating NK receptor DNAM-1. PLoS One (2015) 10:e0125544. doi:10.1371/journal. pone. 0125544

34. de Almeida PE, Meyer EH, Kooreman NG, Diecke S, Dey D, SanchezFreire V, et al. Transplanted terminally differentiated induced pluripotent stem cells are accepted by immune mechanisms similar to self-tolerance. Nat Commun (2014) 5:3903. doi:10.1038/ncomms4903

35. Araki R, Uda M, Hoki Y, Sunayama M, Nakamura M, Ando S, et al. Negligible immunogenicity of terminally differentiated cells derived from induced pluripotent or embryonic stem cells. Nature (2013) 494:100-4. doi:10.1038/ nature11807

36. Andersson G, Illigens BM, Johnson KW, CalderheadD, LeGuern C, Benichou G, et al. Nonmyeloablative conditioning is sufficient to allow engraftment of EGFPexpressing bone marrow and subsequent acceptance of EGFP-transgenic skin grafts in mice. Blood (2003) 101:4305. doi:10.1182/blood-2002-06-1649

37. Andersson G, Denaro M, Johnson K, Morgan P, Sullivan A, Houser S, et al. Engraftment of retroviral EGFP-transduced bone marrow in mice prevents rejection of EGFP-transgenic skin grafts. Mol Ther (2003) 8:385-91. doi:10.1016/S1525-0016(03)00210-7

38. Han WG, Unger WW, Wauben MH. Identification of the immunodominant CTL epitope of EGFP in C57BL/6 mice. Gene Ther (2008) 15:700-1. doi:10.1038/sj.gt.3303104

39. Guha P, Morgan JW, Mostoslavsky G, Rodrigues NP, Boyd AS. Lack of immune response to differentiated cells derived from syngeneic induced pluripotent stem cells. Cell Stem Cell (2013) 12:407-12. doi:10.1016/j.stem. 2013.01.006

40. Morizane A, Doi D, Kikuchi T, Okita K, Hotta A, Kawasaki T, et al. Direct comparison of autologous and allogeneic transplantation of iPSC-derived neural cells in the brain of a nonhuman primate. Stem Cell Reports (2013) 1:283-92. doi:10.1016/j.stemcr.2013.08.007

41. Todorova D, Kim J, Hamzeinejad S, He J, Xu Y. Brief report: immune microenvironment determines the immunogenicity of induced pluripotent stem cell derivatives. Stem Cells (2016) 34:510-5. doi:10.1002/stem.2227

42. Mandai M, Watanabe A, Kurimoto Y, Hirami Y, Morinaga C, Daimon T, et al. Autologous induced stem-cell-derived retinal cells for macular degeneration. N Engl J Med (2017) 376:1038-46. doi:10.1056/NEJMoa1608368
43. Lister R, Pelizzola M, Kida YS, Hawkins RD, Nery JR, Hon G, et al. Hotspots of aberrant epigenomic reprogramming in human induced pluripotent stem cells. Nature (2011) 471:68-73. doi:10.1038/nature09798

44. Chin MH, Mason MJ, Xie W, Volinia S, Singer M, Peterson C, et al. Induced pluripotent stem cells and embryonic stem cells are distinguished by gene expression signatures. Cell Stem Cell (2009) 5:111-23. doi:10.1016/j.stem.2009.06.008

45. Ruiz S, Diep D, Gore A, Panopoulos AD, Montserrat N, Plongthongkum N, et al. Identification of a specific reprogramming-associated epigenetic signature in human induced pluripotent stem cells. Proc Natl Acad Sci U S A (2012) 109:16196-201. doi:10.1073/pnas.1202352109

46. Gore A, Li Z, Fung HL, Young JE, Agarwal S, Antosiewicz-Bourget J, et al. Somatic coding mutations in human induced pluripotent stem cells. Nature (2011) 471:63-7. doi:10.1038/nature09805

47. Li Z, Lu H, Yang W, Yong J, Zhang ZN, Zhang K, et al. Mouse SCNT ESCs have lower somatic mutation load than syngeneic iPSCs. Stem Cell Reports (2014) 2:399-405. doi:10.1016/j.stemcr.2014.02.005

48. Preynat-Seauve O, de Rham C, Tirefort D, Ferrari-Lacraz S, Krause KH, Villard J. Neural progenitors derived from human embryonic stem cells are targeted by allogeneic $\mathrm{T}$ and natural killer cells. J Cell Mol Med (2009) 13:3556-69. doi:10.1111/j.1582-4934.2009.00746.x

49. Swijnenburg RJ, Tanaka M, Vogel H, Baker J, Kofidis T, Gunawan F, et al. Embryonic stem cell immunogenicity increases upon differentiation after transplantation into ischemic myocardium. Circulation (2005) 112:I166-72. doi:10.1161/CIRCULATIONAHA.104.525824

50. Swijnenburg RJ, Schrepfer S, Govaert JA, Cao F, Ransohoff K, Sheikh AY, et al. Immunosuppressive therapy mitigates immunological rejection of human embryonic stem cell xenografts. Proc Natl Acad Sci U S A (2008) 105:12991-6. doi:10.1073/pnas. 0805802105

51. Fife BT, Bluestone JA. Control of peripheral T-cell tolerance and autoimmunity via the CTLA-4 and PD-1 pathways. Immunol Rev (2008) 224:166-82. doi:10.1111/j.1600-065X.2008.00662.x

52. Francisco LM,SagePT,SharpeAH. ThePD-1 pathwayin tolerance and autoimmunity. Immunol Rev (2010) 236:219-42. doi:10.1111/j.1600-065X.2010.00923.x

53. Keir ME, Butte MJ, Freeman GJ, Sharpe AH. PD-1 and its ligands in tolerance and immunity. Annu Rev Immunol (2008) 26:677-704. doi:10.1146/annurev. immunol.26.021607.090331

54. Raker VK, Domogalla MP, Steinbrink K. Tolerogenic dendritic cells for regulatory T cell induction in man. Front Immunol (2015) 6:569. doi:10.3389/ fimmu.2015.00569

55. Szot GL, Yadav M, Lang J, Kroon E, Kerr J, Kadoya K, et al. Tolerance induction and reversal of diabetes in mice transplanted with human embryonic stem cell-derived pancreatic endoderm. Cell Stem Cell (2015) 16:148-57. doi:10.1016/j.stem.2014.12.001

56. Pearl JI, Lee AS, Leveson-Gower DB, Sun N, Ghosh Z, Lan F, et al. Short-term immunosuppression promotes engraftment of embryonic and induced pluripotent stem cells. Cell Stem Cell (2010) 8:309-17. doi:10.1016/j.stem.2011.01.012

57. Alegre ML, Florquin S, Goldman M. Cellular mechanisms underlying acute graft rejection: time for reassessment. Curr Opin Immunol (2007) 19:563-8. doi:10.1016/j.coi.2007.07.019

58. Valujskikh A. The challenge of inhibiting alloreactive T-cell memory. Am J Transplant (2006) 6:647-51. doi:10.1111/j.1600-6143.2005.01215.x

59. He J, Rong Z, Fu X, Xu Y. A safety checkpoint to eliminate cancer risk of the immune evasive cells derived from human embryonic stem cells. Stem Cells (2017) 35:1154-61. doi:10.1002/stem.2568

60. Deuse T, Seifert M, Tyan D, Tsao PS, Hua X, Velden J, et al. Immunobiology of naïve and genetically modified HLA-class-I-knockdown human embryonic stem cells. J Cell Sci (2011) 124:3029. doi:10.1242/jcs.104125

61. Deuse T, Seifert M, Phillips N, Fire A, Tyan D, Kay M, et al. Human leukocyte antigen I knockdown human embryonic stem cells induce host ignorance and achieve prolonged xenogeneic survival. Circulation (2011) 124:S3-9. doi:10.1161/CIRCULATIONAHA.111.020727

62. Lu P, Chen J, He L, Ren J, Chen H, Rao L, et al. Generating hypoimmunogenic human embryonic stem cells by the disruption of beta 2-microglobulin. Stem Cell Rev Rep (2013) 9:806-13. doi:10.1007/s12015-013-9457-0

63. Chen H, Li Y, Lin X, Cui D, Cui C, Li H, et al. Functional disruption of human leukocyte antigen II in human embryonic stem cell. Biol Res (2015) 48:59. doi:10.1186/s40659-015-0051-6 
64. Zheng D, Wang X, Xu RH. Concise review: one stone for multiple birds: generating universally compatible human embryonic stem cells. Stem Cells (2016) 34:2269-75. doi:10.1002/stem.2407

Conflict of Interest Statement: The authors declare that the research was conducted in the absence of any commercial or financial relationships that could be constructed as a potential conflict of interest.
Copyright (C) $2017 \mathrm{Liu}, \mathrm{Li}$, Fu and Xu. This is an open-access article distributed under the terms of the Creative Commons Attribution License (CC BY). The use, distribution or reproduction in other forums is permitted, provided the original author(s) or licensor are credited and that the original publication in this journal is cited, in accordance with accepted academic practice. No use, distribution or reproduction is permitted which does not comply with these terms. 